\title{
A STUDY ON VARIATIONS IN ORIGIN AND COURSE OF RIGHT HEPATIC ARTERY
}

\section{S. Priyadharshini ${ }^{1}$, Chavalin V Bharath ${ }^{* 2}$, P.Bapuji ${ }^{3}$, V.Nagaguhan ${ }^{4}$.}

${ }^{1}$ Associate professor, Department of Anatomy, Alluri sitaramaraju academy of medical sciences, Malakkapuram, Eluru, West Godavari, Andhra Pradesh, India.

${ }^{* 2}$ Assistant professor, Department of Anatomy, Alluri sitaramaraju academy of medical sciences, Malakkapuram, Eluru, West Godavari, And hra Pradesh, India.

${ }^{3}$ Professor \& Head, Department of Anatomy, Alluri sitaramaraju academy of medical sciences, Malakkapuram, Eluru, West Godavari, Andhra Pradesh, India.

${ }^{4}$ Assistant Professor, Department of Biochemistry, All India Institute of medical sciences, Mangalagiri, Guntur, Andhra Pradesh, India.

\section{ABSTRACT}

Background: With ever increasing load of liver disease on population of developed as well as developing countries, it has become mandatory to have a detailed knowledge about hepatic arteries. Since adequate literature regarding hepatic arteries and its variation e in people living in and around Eluru is not available, a study of hepatic arteries ad its variation is carried out in our ASRAM medical college, Andhra Pradesh, India.

Aims and objectives: To study the variations in the origin, course of right hepatic artery

Materials and methods: This study was conducted in 60 embalmed adult cadavers of both sexes of age group between 50 to 80 years. The common hepatic artery and its branch gastroduodenal artery were identified. Proper hepatic artery in the hepatoduodenal ligament was traced and the relation of the common hepatic artery and the proper hepatic artery were noted. Origin of the RHA was traced and the presence of aberrant right hepatic arteries: (i) Replaced; (ii) Accessory were noted. To identify the presence of aberrant right hepatic arteries, abdominal aorta was exposed from the level of origin of the coeliac trunk to the level of origin of the inferior mesenteric artery.

Results: In this study, the right hepatic artery originates from the proper hepatic artery in 24 (60\%) specimens.The aberrant, accessory and replaced right hepatic artery were found to be $20 \%, 12.5 \%$, and $7.5 \%$ respectively. $5 \%$ of specimen showed caterpillar hump in right hepatic artery.

Conclusion: Right hepatic artery is subject to anatomical variation in its origin and course. Because of anatomic variations in the RHA, surgical injuries in the liver can occur even by the most experienced surgeon. A thorough knowledge of the RHA anatomy is necessary while performing hepatic surgery and hepatic arteriography

KEY WORDS: Right Hepatic Artery, Hepatic Artery, Hepatic Artery Variations.

Corresponding Author: Dr. Chavalin V Bharath, Assistant professor, Department of Anatomy, Alluri sitaramaraju academy of medical sciences, Malakkapuram, Eluru, West Godavari, Andhra Pradesh, India. E-Mail: chavalinvbharath@gmail.com

Access this Article online

Quick Response code

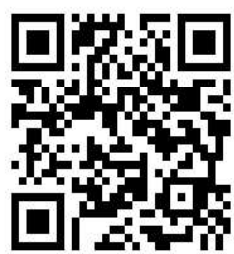

DOI: $10.16965 /$ ijar.2019.340

Journal Information

\section{International Journal of Anatomy and Research}

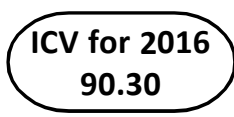

ISSN (E) 2321-4287 | ISSN (P) 2321-8967

https://www.ijmhr.org/ijar.htm

DOI-Prefix: https://dx.doi.org/10.16965/ijar

\section{(c) $\overline{B r}+\mathrm{Mt}-\mathrm{BA}$}

\section{Article Information}

Received: 13 Nov 2019

Peer Review: 13 Nov 2019

Revised: None
Accepted: 12 Dec 2019
Published (O): 05 Jan 2020
Published (P): 05 Jan 2020

\section{INTRODUCTION}

Liver possesses dual blood supply; hepatic artery and the portal vein shares the vascularization of the organ. In general, the common 
Liver possesses dual blood supply; hepatic artery and the portal vein shares the vascularization of the organ. In general, the common hepatic artery may arise from the abdominal aorta or superior mesenteric artery (SMA) and all or part of the right and left hepatic arteries may arise from (be replaced to) other vessels.

Another common finding, though not considered a variant by many authors, is trifurcation of the common hepatic artery into the right hepatic artery, left hepatic artery and gastroduodenal artery (GDA). With this branching pattern, there is no proper hepatic artery (PHA).

The normal branching pattern of celiac trunk originates the common hepatic artery that divides itself forming the gastroduodenal artery and the proper hepatic artery. The proper hepatic artery divides into right and left hepatic arteries. The other branches are splenic artery and left gastric artery.This classical type of coeliac trunk is known as trifurcation and was first observed by Haller as tripusHalleri."

Variations of the hepatic artery of liver and its branches are exceedingly common. Variations in the origin and number of the hepatic arteries may be facilitated by defining the terms commonly used in describing such variations. These terms are "aberrant", "accessory", and "replacing". A typical "normal" right hepatic artery (RHA) arises from the proper hepatic artery and supplies the right lobe of liver [1].

An aberrant RHA is one that arises from some other source than the proper hepatic artery. If an aberrant artery supplies the right lobe of the liver, the right lobe also receives supply from the proper hepatic artery of normal origin it is known as an aberrant accessory RHA. If an aberrant RHA constitutes the sole blood supply to the right lobe of the liver it is known as an aberrant replacing right hepatic artery, since it replaces the normal RHA [2].

Variations in the normal pattern are described by Abdullah et al [3], always highlighting the most common patterns of variation, such as accessory hepatic arteries from the superior

mesenteric or from the left gastric artery [4]. The two most common variants are replaced right hepatic artery arising from the SMA and replaced left hepatic artery arising from the left

\section{gastric artery}

Hepatic arterial perfusion scintigraphy, Transhepatic Arterial Chemoembolization (TACE) and Hepatic Arterial Infusion (HAI) chemotherapy are the newer therapeutic techniques used in the treatment of primary and metastatic hepatic tumors that derive most of its blood supply from the hepatic artery [5].

A thorough knowledge of the RHA anatomy is necessary while performing hepatic surgery and hepatic arteriography. Because of anatomic variations in the RHA, surgical injuries in the liver can occur even by the most experienced surgeon [2].

AIM AND OBJECTIVES: To find out the variations in the origin, course of right hepatic artery.

\section{MATERIALS AND METHODS}

The study was conducted on 40 embalmed cadavers of both sexes in ASRAM medical college, Eluru during 2017-19.Abdomen was opened by a midline linear incision extending from xiphoid process to pubic symphysis. Anterior layer of peritoneum was removed from the lesser omentum close to the lesser curvature of the stomach. Coeliac trunk arising as a ventral branch from the abdominal aorta was traced. Origin of the common hepatic artery from the coeliac trunk, aorta and superior mesenteric artery (SAM) was traced. The common hepatic artery and its branch gastroduodenal artery were identified. Proper hepatic artery in the hepatoduodenal ligament was traced and the relation of the common hepatic artery and the proper hepatic artery were noted. Origin of the RHA was traced and the presence of aberrant right hepatic arteries: (i) Replaced; (ii) Accessory, were noted. To identify the presence of aberrant right hepatic arteries, abdominal aorta was exposed from the level of origin of the coeliac trunk to the level of origin of the inferior mesenteric artery. Presence of an accessory or replaced right hepatic artery arising from the superior mesenteric artery, RHA and inferior mesenteric artery were noted. All this steps were done as per the guidance of cunninghams manual. The course of normal and aberrant RHA from its origin to entrance into the right lobe of the liver was traced and structures related to it were noted. 
Statistical Analysis: We used simple proportion (frequency analysis) with the help of Open Epi Version 3.0 software.

\section{RESULTS}

Out of 40 specimens the origin of right hepatic artery from proper hepatic artery is $24(60 \%)$. The remaining specimens shows variations as follows

The variations seen in the origin of right hepatic artery are shown in table 1

Table 1: variations in the right hepatic artery.

\begin{tabular}{|c|c|c|}
\hline Variations in the RHA & $\begin{array}{c}\text { Number of } \\
\text { variations }\end{array}$ & Frequency (\%) \\
\hline Aberrant RHA & 8 & 20 \\
\hline Accessory RHA & 5 & 12.5 \\
\hline Replaced RHA & 3 & 7.5 \\
\hline
\end{tabular}

Fig. 1: Replaced RHA arising from superior mesenteric artery.

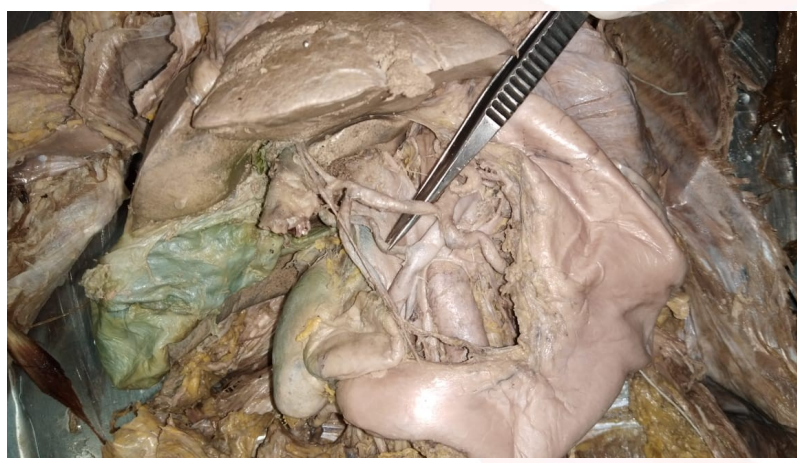

Fig. 2: Accessory RHA arising from superior mesenteric artery.

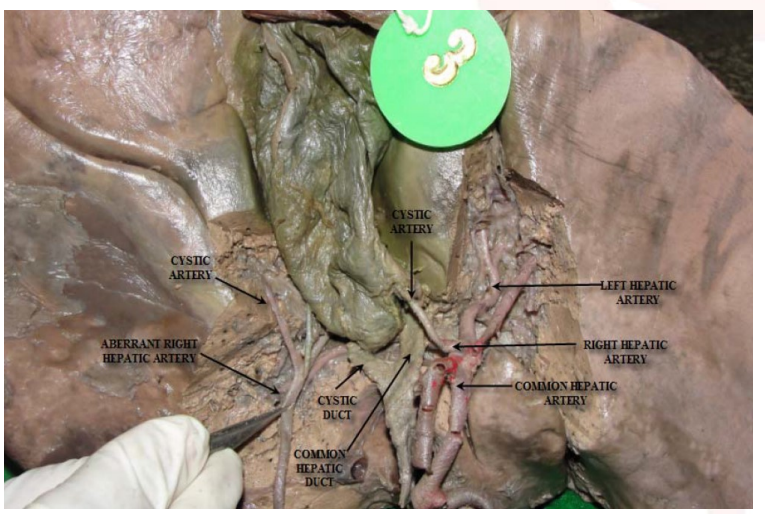

Fig. 3: RHA passing dorsal to the common hepatic duct.

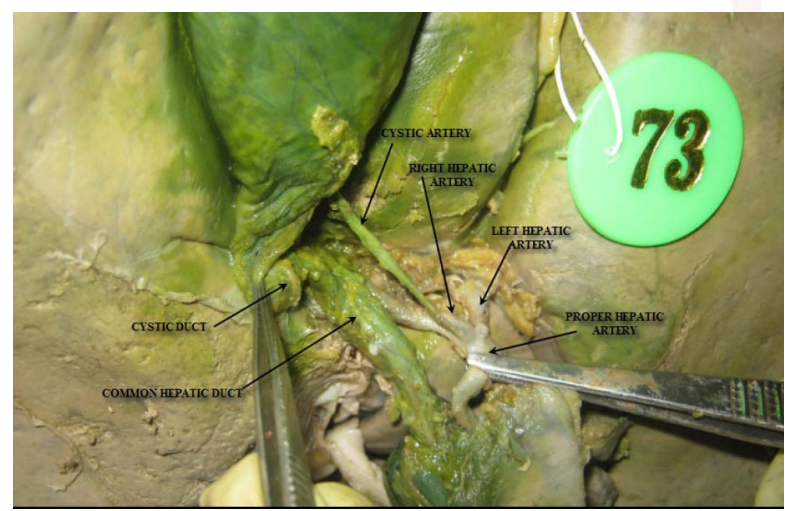

Int J Anat Res 2020, 8(1.1):7207-11. ISSN 2321-4287
Fig. 4: Caterpillar hump of RHA.

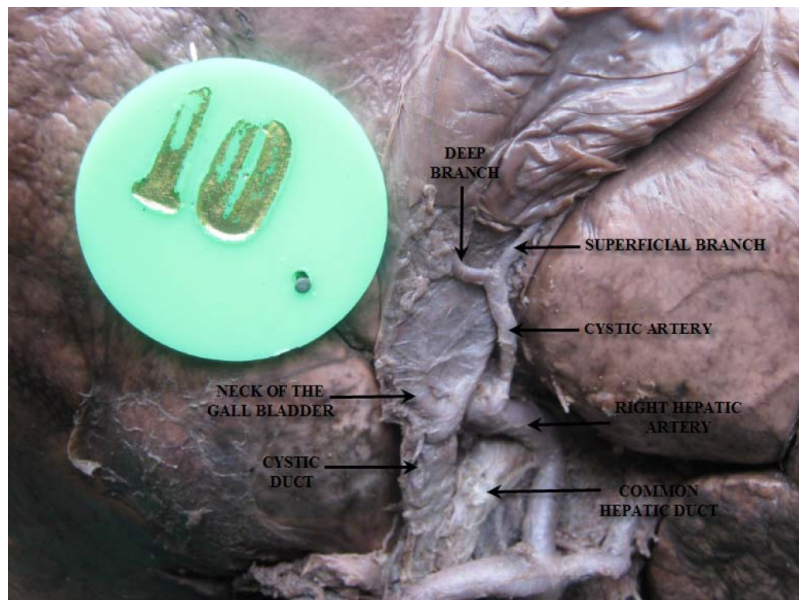

Fig. 5: Showing a) Accessory LHA b) origin of cystic artery from LHA.

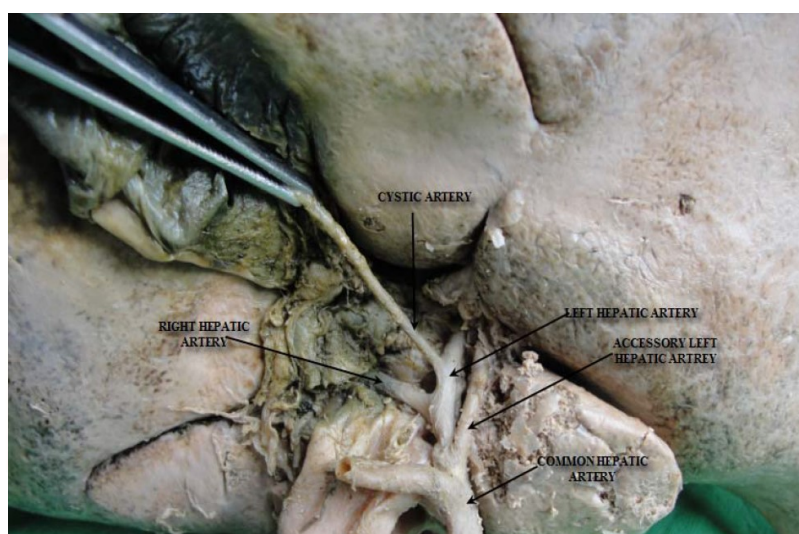

Out of 40 cadavers, there are $3(7.5 \%)$ replaced RHA. In all the cases the replaced artery arises from superior mesenteric artery (fig.1).

Out of 40 cadavers dissected, accessory RHA arises from SMA is in 5(12.5\%) specimens while RHA originates from proper hepatic artery (fig.2).

Out of 40 cadavers dissected, in 32 specimens the RHA is a branch of proper hepatic artery and it passes in front of the portal vein from left to right and posterior to the common hepatic duct to enter the Calot's triangle where the RHA gives origin to cystic artery and then it turned upward behind the right hepatic duct to enter the right lobe of liver as shown in the figure 3.

The presence of caterpillar hump should be suspected when an unusally large cystic artery is viewed through the laproscope and the surgeons can save the patient from the iatrogenic ischemic necrosis of right lobe of liver (fig.4)

During routine dissection variations also observed in left hepatic artery as accessory left hepatic artery and origin of cystic artery from left hepatic artery as shown in figure 5 . 
These aberrant arteries can be attributed to abnormal persistence or regression of embryonic arteries. In early human embryos (4-17mm) the omphalomesenteric artery (superior mesenteric artery) arises by four roots (10th, 11th, 12th and13th ventral segmentals) which are united by ventral longitudinal anastomosis running parallel to the aorta. Normally greater part of this ventral longitudinal anastomosis disappears as do the two middle roots (11th and 12th) leaving the first root to become stem of celiac and last root to become stem of superior mesenteric artery. The ventral longitudinal anastomosis between the roots of primitive vitelline arteries is the common source of origin of all the branches of celiac artery and of accessory hepatic arteries, persistence of interrupted sections accounting for aberrancy in origin of regional arteries [6].

According Taylor et al, caterpillar hump formation in RHA is more liable to become elongated and tortuous during cirrhosis of liver, and they emphasis that it may be due to underlying structural distortion associated with coiling of intrahepatic branches of hepatic artery[7]. Caterpillar hump (Moynihan hump) of right hepatic artery was present in 2 specimens ( 3.33 $\%$ ) in their study when compared to $5 \%$ in the present study (fig 4). By comparing the previous studies the incidence of caterpillar hump varies between $3 \%-5 \%$.

The study conducted by Balija et al[8], the cystic artery origin from LHA is $1 \%$. In our present study in one specimen cystic artery from LHA, passes through the liver parenchyma, and reaches the middle of the gallbladder body. In the same specimen we got an accessory LHA from the proper hepatic artery (fig.5). In such a case it usually travels through a passage of liver parenchyma, approaching the neck of the gallbladder, before bifurcating into ascending (or superior) and descending (or inferior) branches. By comparing the results of various authors (table 2) [9-14], about the aberrant hepatic arteries our study results are on par with

In our present study, the RHA passes dorsal to the hepatic duct (fig 3 ) in all the specimens which is not par with the findings of Nicholas, RHA may have a retrobiliary course in $85 \%$ (dorsal to duct system) and prebiliary course in
$15 \%$ (ventral to duct system)[2].

Marcos et al in 2003[13] states that replaced RHA is an advantageous variant in case living liver donors. The hepatic artery thrombosis is the commonest complication to be encountered by these patients due to thin and short hepatic arterial graft. But replaced RHA is longer and thicker enough to avoid these complications.

Table 2: Comparison of incidence of aberrant hepatic artery by various authors.

\begin{tabular}{|l|c|c|}
\hline \multicolumn{1}{|c|}{ Authors } & $\begin{array}{c}\text { Accessory hepatic } \\
\text { artery[\%] }\end{array}$ & $\begin{array}{c}\text { Replaced hepatic } \\
\text { artery[\%] }\end{array}$ \\
\hline Thangarajah A and Ramesh P 2016 [10] & 9 & 3.5 \\
\hline George Noussios et al. 2017 [14] & 3.7 & 3.2 \\
\hline $\begin{array}{l}\text { Narayanaperumal Mugunthan et al. } \\
\text { 2012 [12] }\end{array}$ & 8.3 & 5 \\
\hline Adachi 1928 [9] & 12.3 & - \\
\hline Nicholas A.Michels et al. 1966 [6] & 18 & 8 \\
\hline Molmenti et al. 2003 [11] & $15-20$ & 5 \\
\hline Present study [2019] & 12.5 & 7.5 \\
\hline
\end{tabular}

\section{CONCLUSION}

The knowledge of different hepatic arterial pattern is more important as we are curious about minimal invasive techniques. These informations will reduce the iatrogenic complications and better outcome. To conclude hepatic arterial anatomy contributes one of the important lessons learnt by the general surgeons.

\section{ACKNOWLEDGEMENTS}

We acknowledge the faculties and staffs of Anatomy, Alluri Sitaramaraju Academy of Medical Sciences, who actively participated in the current study.

\section{Conflicts of Interests: None}

\section{REFERENCES}

[1]. Poynter CWM. Congenital anomalies of the arteries and veins of the human body with bibliography. The University studies of the University of Nebraska, Lincoln.1922. 22:1-106.

[2]. Michels NA. Blood supply and anatomy of the upper abdominal organs with a descriptive atlas. Philadelphia and Montreal, B. Lippincott Company.1955;134-83.

[3]. Abdullah SS, Mabrut JY, Garbit V, De La Roche E, Olagne E, Rode A, Morin A, Berthezene Y, BaulieuxJ, Ducerf $C$. Anatomical variations of the hepatic artery: study of 932 cases in liver transplantation. Am J Surg 2006; 28(5): 468-473.

[4]. Gruttadauria S, Scotti Foglieni C, Doria C, Luca A,Lauro A, Marino IR. The hepatic artery in liver transplantationand surgery: vascular anomalies in 701cases. Clin Transplant 2001; 15: 359-363. 
[5]. Padhy AK. Radionuclide scintigraphy in hepatobiliary and splenic diseases.GI Surgery Annual. 1996;3:115-20.

[6]. Michels NA. Newer anatomy of the liver and its variantblood supply and collateral circulation. Am J Surg 1966; 112: 337-347.

[7]. Taylor CR (20 November 2013).Cirrhosis imaging.Available: http:// www.emedicine. medscape .com/article/ 366426 - overview, [ Accessed 28 December2019]

[8]. Balija M, Huis M, Nikolic V, Stulhofer M. Laparoscopic visualization of the cystic artery anatomy. World J Surg. 1999;23:703-707; discussion 707.

[9]. Adachi B. Das arterien system der japaner, tokyo, kenkyusha press,1928: 28-54.

[10]. Thangarajah A, Parthasarathy R. Celiac Axis, Common. Hepatic and hepatic artery variants as evidenced on MDCT angiography in south indian population. Journal of Clinical and Diagnostic Research: JCDR. 2016;10(1):TC01-5.
[11]. Molmenti EP, Pinto PA, Klein J, Klein AS. Normal and variant arterial supply of the Liver and Gall Bladder. Pediatr Transpl. 2003;7:80-82.

[12]. Mugunthan N, Jansirani D, Felicia C, Anbalagan J. Anatomical variations in the arterial supply of liver. International Journal of Anatomical Variations 2012;5:107-9.

[13]. Marcos A, Killackey M, Orloff MS, Mieles L, Bozorgzadeh A, Tan HP. Hepatic arterial reconstruction in 95 adult right lobe living donor liver transplants: evolution of anastomotic technique. Liver Transplantation. 2003 Jun 1;9(6):570-4.

[14]. Noussios G, Dimitriou I, Chatzis I, Katsourakis A. The main anatomic variations of the hepatic artery and their importance in surgical practice: review of the literature. Journal of clinical medicine research. 2017 Apr;9(4):248.

How to cite this article:

S. Priyadharshini, Chavalin V Bharath, P.Bapuji, V.Nagaguhan. A STUDY ON VARIATIONS IN ORIGIN AND COURSE OF RIGHT HEPATIC ARTERY. Int J Anat Res 2020;8(1.1):7207-7211. DOI: 10.16965/ijar.2019.340 